\title{
Expectations Concordance and Stock Market Volatility: Knightian Uncertainty in the Year of the Pandemic
}

\author{
Roman Frydman ${ }^{*}$ and Nicholas Mangee **
}

\author{
Working Paper No. 164
}

September $5^{\text {th }}, 2021$

\begin{abstract}
This study introduces a novel index based on expectations concordance for explaining stock-price volatility when historically unique events cause unforeseeable change and Knightian uncertainty in the process driving outcomes. Expectations concordance measures the degree to which nonrepetitive events are associated with directionally similar expectations of future returns. Narrative analytics of daily news reports allow for assessment of bullish versus bearish views in the stock market. Increases in expectations concordance across all KU events leads to reinforcing effects and an increase in stock market volatility. Lower expectations concordance produces a stabilizing effect wherein the offsetting views reduce market volatility. The empirical findings hold for ex post and ex ante measures of volatility and for OLS and GARCH estimates.
\end{abstract}

https://doi.org/10.36687/inetwp164

JEL Codes: D81; D84; G12; G14.

Keywords: expectations concordance, narrative analytics, volatility, Knightian uncertainty

\footnotetext{
* Department of Economics, New York University, roman.frydman@nyu.edu, 212-998-8967, Institute of New Economic Thinking Program on Knightian Uncertainty Economics

** Department of Finance, Parker College of Business, Georgia Southern University, nmangee@georgiasouthern.edu, 912-344-3240, Institute of New Economic Thinking Program on Knightian Uncertainty Economics
} 


\section{Introduction}

Many macro events, such as Congressional stimulus negotiations or a pandemic, but also firmlevel events, such as bankruptcies or legal issues, contribute to stock market volatility. Such events are non-repetitive in nature, each being somewhat historically unique in its occurrence. Because participants cannot rely on ex ante distributions based on past data when forecasting returns, they instead form qualitative views about whether such events will have a bullish or bearish impact.

Understanding the influence of non-repetitive historical events - and the Knightian uncertainty (KU) they engender - in the process driving stock market volatility presents serious challenges for researchers. ${ }^{1}$ It is not clear how to identify and measure participants' qualitative interpretations in direct response to a particular KU event, or how to represent the broad market's expectation when facing a diversity of views about concurrent events. How might researchers address whether these views are more concordant (similar) or discordant (conflicting) on the whole for returns at a given point in time?

Dynamic general equilibrium and ARCH-type models typically represent time-varying volatility in stock returns with a stochastic process and, consequently, assume away uncertainty arising from KU events. ${ }^{2}$ Other approaches focusing on news dispersion effects construct sentiment indices based on the optimistic versus pessimistic tone of textual data from financial reports. ${ }^{3}$ However, these methodologies often focus on word counts or net linguistic tone to proxy for participants' interpretations. One reasonable hypothesis is that when the concordance of views in response to KU events is low (i.e., greater conflict), so is market volatility, and vice versa, as the bullish versus bearish views to some extent offset and stabilize price fluctuations. Studies tracking the frequency of "uncertainty" terms or sentiment would be unable to address this hypothesis. ${ }^{4}$

\footnotetext{
${ }^{1}$ Knight (1921) argues that change in the distribution characterizing outcomes is unforeseeable: structural breaks often occur contemporaneously with historical events which "are far too unique for any sort of statistical tabulation to have any value for guidance" (p. 231). The resulting uncertainty cannot "by any method...be reduced to an objectively measurable probability” (p. 231, 321). For recent evidence in support of Knight's views, see Hendry and Doornik (2014), Hendry (2018), Frydman et al. (2015), Mangee and Goldberg (2020), and Mangee (2021a,b).

${ }^{2}$ For seminal stochastic volatility models based on dynamic general equilibrium, see Hull and White (1987) and Wiggins (1987). For ARCH models, see the seminal study by Engle (1982). See also Campbell et al. (2018) and Cochrane (2005) and references therein.

${ }^{3}$ Models of disagreement typically rely on probabilistic representations of heterogeneous beliefs and, thus, assume away Knightian uncertainty. See Hong and Stein (2007), Barinov (2013), Hansen (2015), and Branger et al. (2015). ${ }^{4}$ See Baker et al. (2016), Baker et al. (2020b), Manela and Moreira (2017), Liu and Zhang (2015), Bekiros et al. (2016), Friberg and Seiler (2016), Alexopoulos and Cohen (2017), Dzielinski and Hasseltoft (2017), and Loughran and MacDonald (2011). Baker et al. (2019) take a more narratological approach based on human scoring of news after trading days with the largest changes in stock market prices.
} 
Here, we fill this gap in the literature by constructing an index that directly relates a particular event's bullish or bearish interpretations to stock return expectations, rather than relying on word counts or sentiment. We formulate an index of aggregate expectations concordance based on coding of narrative accounts from Bloomberg News daily stock market wrap reports for 2020. By scoring $+1 \mathrm{~s}$ and $-1 \mathrm{~s}$ for each relevant event's interpreted impact on returns, we are able to measure the degree to which bullish and bearish views are more concordant or discordant on the whole for future returns. Our Expectations Concordance Index (ECI) is able to track both the interpretations of a particular KU event over time and the interpretations across all relevant events at a point in time. Time-series plots illustrate that ECI fluctuates dramatically between concordance and discordance throughout the 220 trading days in the sample period. Our analysis yields four key findings.

First, the narrative accounts provide evidence on the overall importance of non-repetitive events for driving fluctuations in daily stock returns. In fact, the Bloomberg reports indicate that such events were deemed relevant for market expectations on roughly $90 \%$ of the trading days in the sample. The greatest variance in expectations concordance involves KU events from the categories of Government, Firm-Level, Central Bank, Pandemic, President Trump, and Rest-ofWorld. Perhaps unsurprisingly, KU events associated with the COVID-19 pandemic, such as cases, deaths, and vaccination trials, were most often reported as driving stock prices in 2020, mattering on over $57 \%$ of the total trading days. Time-series plots illustrate that when periods of high COVID-19 new cases and growth rates align with the passage of the first and second Congressional stimulus packages, aggregate ECI is low, reflecting the conflicting bearish versus bullish views, respectively. ${ }^{5}$

Second, formal empirical analysis supports our hypothesis: increases in aggregate ECI lead to an increase in stock market volatility. This result is robust to explaining the realized volatility of S\&P500 returns, the absolute magnitude of S\&P500 returns, and the implied volatility of the VIX. The findings suggest that greater expectations concordance, whether bullish or bearish, has a reinforcing effect that increases market volatility. Lower expectations concordance produces a stabilizing effect wherein the offsetting views reduce market volatility. Furthermore, ECI is found to Granger-cause the VIX, but not the other way around.

The third main finding is that augmenting a simple GARCH-X model by including ECI in the variance process produces hypothesized signs on coefficients. The results are robust to both realized and implied volatility and to specifications where expectations concordance is also included in the mean equation. Including ECI for realized volatility also leads to improvements in residual diagnostics and reductions in overall persistence. Lastly, we explore how ECI can augment traditional notions of risk in explaining implied volatility. Empirical findings from OLS

\footnotetext{
${ }^{5}$ Baker et al. (2020a) use automated and manual news analytics to document the historically unprecedented influence the COVID-19 pandemic has had on the US stock market compared to previous pandemics.
} 
regressions suggest that information sets including both fundamental risk and KU-based ECI offers a better overall fit for modeling the VIX.

The paper is structured as follows. Section 2 describes the data and provides descriptive statistics about the frequency of KU events reported in the Bloomberg News wraps as driving daily stock returns. The methodology of the expectations concordance index is then presented along with the aggregate ECI index and accompanying time-series plot. Periods are discussed where ECI is historically high or low over the 2020 sample period. Section 3 presents the empirical results and Section 4 provides concluding remarks.

\section{Data and Methodology}

Although at least one historical event during 2020 was reported as driving stock returns from categories such as Analyst Ratings, Benchmark Valuation, Commodities, Currency Markets, Financial Institutions, Geopolitical Issues, Housing, Oil, and Trade, the most important KU events come from the categories of Central Bank, Company Variables, Government (and President Trump), Pandemic, and Rest of World. Table 1 lists the disaggregated events within these KU categories. The category Pandemic, for instance, contains news about COVID cases, deaths, testing, and vaccination trials. Government includes Congressional stimulus and President Trump-related events, and so on. 
Table 1: KU Factor Disaggregated Classification

\begin{tabular}{|l|l|}
\hline Central bank & Government \\
\hline monetary policy & fiscal policy \\
\hline comments by officials & comments by officials \\
\hline macroprudential policy/stimulus & Trump Tweets/comments/orders \\
\hline & Trump health \\
\hline Company variables & Trump legal issues \\
\hline bankruptcy & Congressional stimulus/ negotiations \\
\hline executive turnover/health & regulatory policy \\
\hline legal/accounting issues & taxes/rules on CEO bonuses \\
\hline firm added to index & government shutdown \\
\hline executive salary & impeachment issues \\
\hline assets & military spending \\
\hline reorganization/spinoffs/partnerships & austerity measures \\
\hline liabilities/debt & sovereign credit worthiness/rating \\
\hline share issuances & bailout/nationalization of industry \\
\hline IPO & healthcare issues \\
\hline business spending & political instability/corruption \\
\hline mergers \& acquisitions & presidential election issues \\
\hline accident/recall/data breach & Biden/democratic election prospects \\
\hline price target announcements & Trump/republican election prospects \\
\hline new products/production processes & Congressional testimony \\
\hline insider trading & cabinet/supreme court appointments \\
\hline credit/credit ratings & Pandemic \\
\hline resource discovery & COVID cases/deaths/testing \\
\hline labor layoff/strike/union & COVID vaccination \\
\hline CEO/executive comments & \\
\hline purchase/sale of large stake & Rest of world \\
\hline stock split & any factor pertaining to another country \\
\hline share buyback & \\
\hline & \\
\hline ing & \\
\hline & \\
\hline
\end{tabular}

Notes: The table lists the most important categories and subcategories of KU events as reported in Bloomberg News stock market wrap reports during 2020.

\subsection{News Scoring}

To formalize what is meant by bullish or bearish expectations, a quantifiable measure must be applied to the sign of interpretations of KU events' impact on returns based on the Bloomberg News market wraps. KU factors are not measured on a quantitative scale of magnitude like, say, earnings, interest rates, CPI, or jobless claims. Here, the reported bullish (bearish) impact of KU events on expectations is captured with a $+1(-1)$ and 0 otherwise. 
Consider the following wrap excerpt, which illustrates how multiple KU events on a given trading day can lead to higher expectations concordance for returns:

"U.S. stocks started December by rising to record highs as a renewal of aid talks added to optimism over progress on coronavirus vaccines...House Speaker Nancy Pelosi delivered a new proposal for a stimulus package and Senate Majority Leader Mitch McConnell said Tuesday he is circulating among Republicans his own revised plan, which has the backing of President Donald Trump. " [12/1/20]

This excerpt would receive $\mathrm{a}+1$ for stimulus, $\mathrm{a}+1$ for vaccine, and +2 for Government official comments, since the data also tracks the count of KU events (Pelosi and McConnell). These scores reflect a high degree of reinforcing bullish interpretations in this particular excerpt on that particular day and, thus, greater expectations concordance.

Trading days across the year witnessed many instances in which KU events within the aforementioned categories produced concordant expectations generating either a bullish or bearish overall view of future returns. Success in a vaccine trial stage may be announced on the same day that officials from Congress document progress in advancing a stimulus bill. Both of these KU events may produce bullish expectations for future returns. Alternatively, news of an outbreak of COVID cases, coupled with news of large corporate layoffs, may be interpreted by investors as reinforcing a bearish outlook for returns. In both cases, there is a higher degree of expectations concordance in response to KU events.

Interpretations of KU events' impact on returns could also be conflicting, or less concordant, through concurrent news about, say, Presidential comments signaling support for an aid package coupled with a dire warning from the Fed Chair about economic growth. This form of conflict occurs across KU events at a point in time. Lower expectations concordance may also occur within a particular KU event-category over a recent stretch of time. Consider the following two wrap report excerpts from October 21 and October 23, respectively, showing lower expectations concordance within a particular KU factor (Congressional stimulus) for returns over a recent stretch of trading days:

U.S. stocks ended a volatile session slightly lower as the White House and Democrats neared an aid deal but signaled it's unlikely to become law before the election. "You look at the trading today and it's almost like watching a cat with a laser pointer," Mark Hackett, chief of investment research at Nationwide, said by phone. "Pelosi comes out midday and says she's excited about the deal, and then two minutes later says she doesn't think a deal will get done, and the market's reacting. Investors are fixated on the shiny object, which is the stimulus deal." 
Most U.S. stocks rose after the Trump administration resuscitated hopes for a spending package. Investors remain focused on Washington, where lawmakers are haggling over a financial spending bill to prop up the economy before Nov. $3 \ldots$

These excerpts suggest that stimulus prospects were viewed bearishly (-1) on October 21, but bullishly $(+1)$ on October 23 , which suggests a temporal conflict of interpretation attached to federal stimulus measures for future returns. Government official statements for Pelosi were also ultimately viewed as bearish on October 21 (-1).

We investigate the following hypothesis implied by expectations concordance and stock market volatility under Knightian uncertainty and unforeseeable change:

(i) greater expectations concordance regarding aggregate $K U$ events' impact leads to greater return volatility and vice versa

Hypothesis (i) suggests that greater expectations concordance, whether bullish or bearish on the whole, has a reinforcing effect that increases market volatility; lower expectations concordance produces a stabilizing effect wherein the offsetting views reduce market volatility.

\subsection{Descriptive Evidence of KU Event Frequency}

The second column of Table 2 reports the percentage of trading days that KU events were reported in Bloomberg News wraps as driving stock returns for 2020. The findings show that KU factors mattered on over $90 \%$ of the 220 total trading days. The most frequently mentioned KU factors in relation to daily price fluctuations were in the categories of Pandemic and Government, which were reported as market drivers on $57 \%$ and $55 \%$ of total trading days, respectively. Central Bank, Rest of World, and Company Variables were the next most-reported KU factors, moving prices on $29 \%, 28 \%$ and $22 \%$ of total trading days, respectively. The third column reports that when KU factors were reported as driving the market, there were 3.64 particular KU events mentioned on those days. At the category level, when Pandemic-related events, for example, mattered for the stock market, there were 1.46 events within that category on an average day. 
Table 2: Factor Frequency of KU Events and Bullish-Bearish Percentiles

\begin{tabular}{|l|c|c|c|}
\hline KU Fundamentals & $\begin{array}{c}\text { \% of trading } \\
\text { days }\end{array}$ & $\begin{array}{c}\text { Number of } \\
\text { mentions/day }\end{array}$ & $\begin{array}{c}\% \text { bullish view } \\
\text { w/ prices }\end{array}$ \\
\hline company variables & 90.4 & 3.64 & $50.7 \%$ \\
\hline FX markets & 22.4 & 1.33 & 53.8 \\
\hline benchmark valuation & .46 & 1.00 & 100 \\
\hline trade & 10.0 & 1.29 & 14.8 \\
\hline housing & 6.9 & 1.07 & 31.3 \\
\hline government & 0.5 & 1.00 & 100 \\
\hline financial institutions & 55.3 & 1.00 & 60.9 \\
\hline Central Bank & 1.0 & 1.00 & 100 \\
\hline commodities & 29.7 & 1.14 & 64.9 \\
\hline oil & 0.5 & 1.00 & 100 \\
\hline geopolitical & 1.4 & 1.00 & 0 \\
\hline natural disaster/climate & 5.9 & 1.08 & 14.3 \\
\hline pandemic & 0 & 0 & $\mathrm{n} / \mathrm{a}$ \\
\hline social issues & 57.5 & 1.46 & 42.9 \\
\hline analyst ratings & 0 & 0 & $\mathrm{n} / \mathrm{a}$ \\
\hline ROW & 2.3 & 1.00 & 60.0 \\
\hline
\end{tabular}

Notes: The table reports the proportion of trading days, average mentions, and proportion of bullish interpretations for different classifications of KU events as identified and scored from Bloomberg News stock market reports for 2020.

A wordcloud of KU factors is presented in Figure 1 (with accompanying histogram in Figure 2) for the 2020 stock market wrap reports. ${ }^{6}$ Wordclouds present the most-often identified words, either in absolute terms or based on some preclassified lexicon, where the size of the words indicates the relative frequency of their occurrence. Figures 1 and 2 illustrate just how important news about "stimulus," "virus," "China," "Trump," and "Democrats" was for the 2020 stock market. This provides suggestive evidence on which KU-based story threads were most prominent for investor forecasts and market volatility throughout the year.

\footnotetext{
${ }^{6}$ The KU dictionary lexicon has also been featured in Mangee (2021b, Chapter 4) and can be found at the coauthor's website, https://www.taskstream.com/ts/mangee/NicholasMangee.
} 
Figure 1: Bloomberg News Wordcloud of KU Factors in 2020

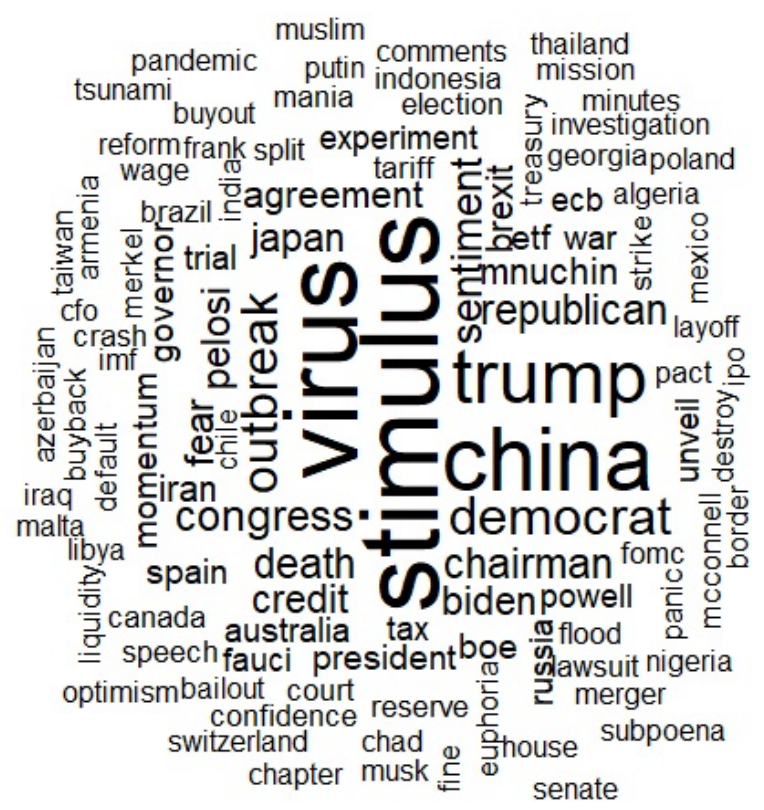

Notes: The Wordcloud is based on the co-author's dictionary lexicon of KU events reported in Bloomberg News stock market wrap reports for 2020 .

Figure 2: Histogram of Absolute Frequencies of KU Terms in 2020

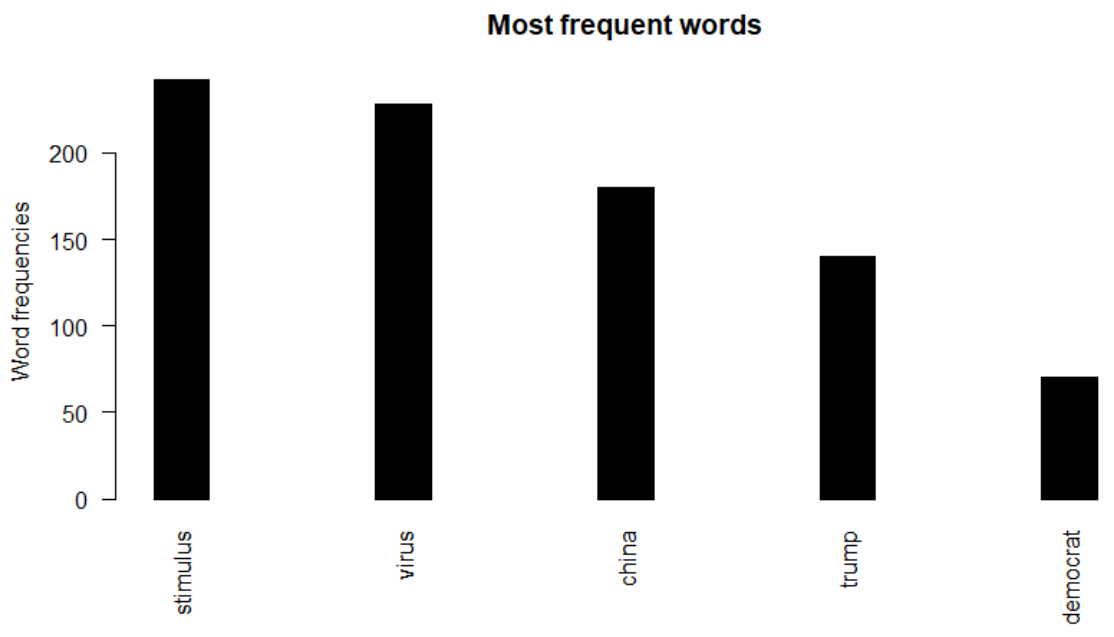

Notes: The figure graphs the frequency of KU event terms as reported in Bloomberg News stock market wrap reports for 2020.

One broad assessment of KU events' expectations concordance/discordance can be obtained by measuring the proportion of mentions that market participants deemed bullish. If it is less than 
$100 \%$ and greater than $0 \%$, then there is evidence of variation between bullish and bearish views within the category over the sample. The last column in Table 2 shows that, in the aggregate, KU factors were roughly split (50.7\%) between bullish and bearish interpretations for the 2020 stock market. This finding suggests that there is a great diversity of views across the sample period, and that the dataset provides a fertile testing ground for the expectations concordance hypothesis for stock market volatility.

At the category level, Pandemic events, for instance, yielded bearish expectations for stock prices for $57 \%$ of total mentions. Central Bank and Government KU event expectations were bullish overall for $65 \%$ and $61 \%$ of mentions, respectively. Reading through the reports, these figures reflect the bullish expectations, on average, of stimulus programs from both the Government and the Federal Reserve and the bearish views generated by COVID-19 cases and deaths. Large diversity of views in response to KU events appears from Table 2 to be more the rule than the exception. Of the 14 categories of KU events, half of them - Company Variables, Trade, Government, Central Bank, Pandemic, Analyst Ratings, and Rest of World - generated a bullish interpretation for returns between $30 \%$ and $70 \%$ of mentions, implying high variation (and low within-category concordance) between bullish and bearish views.

\subsection{Expectations Concordance Index}

Scoring the Bloomberg News stock market reports involves tracking, first, whether a historical event reported as driving stock prices was viewed as impacting returns positively $(+1)$ or negatively (-1). All other factors each day are given a zero. The second determination involves tracking the concordance of count-based $+1 \mathrm{~s}$ and $-1 \mathrm{~s}$ over time. The third determination involves the aggregation of $+1 \mathrm{~s}$ and $-1 \mathrm{~s}$ into an expectations concordance index. For aggregate expectations concordance, consider KU events $i=1, \ldots, \mathrm{n}$ over the previous 10 trading days, where

$$
T_{t \mid t-j}=\sum_{j=0}^{9} \sum_{i=1}^{n}\left|K U_{t-j}^{i}\right|
$$

represents the sum of the absolute value of all KU events' bullish and bearish interpretations. If the sum of the event matrix is expressed as

$$
S_{t \mid t-j}=\sum_{j=0}^{9} \sum_{i=1}^{n} K U_{t-j}^{i}
$$


then the number of positive (i.e., bullish) entries is $P=(T+S) / 2$, and the number of negative (i.e. bearish) entries is $N=(T-S) / 2$ which yields the aggregate expectations concordance index,

$$
E C I_{t \mid t-j}=\frac{\max (P, N)}{T_{t \mid t-j}}
$$

The ECI values are bounded between .5 and 1, where higher values indicate greater concordance of expectations, whether bullish or bearish. Here is how the previous excerpts would produce ECI values. The excerpt from December 1 scored +1 for stimulus, +1 for vaccine and +2 for Government comments. Therefore, $T=|1|+|1|+|2|=4 ; S=1+1+2=4 ; P=\frac{T+S}{2}=4$; $N=\frac{T-S}{2}=0$; and $E C I=\frac{\max (P, N)}{T}=\frac{4}{4}=1$, reflecting the high concordance of bullish views. Alternatively, the two excerpts from October 21 and October 23 scored -1 for stimulus, -1 for Government comments, and +1 for stimulus, implying $T=|-1|+|-1|+|1|=3 ; S=-1+$ $(-) 1+1=-1 ; P=\frac{T+S}{2}=1 ; N=\frac{T-S}{2}=2$; and $E C I=\frac{\max (P, N)}{T}=\frac{2}{3}=.667$, reflecting a lower degree of expectations' concordance. The 10-day aggregate ECI will serve as the key explanatory variable in OLS and GARCH regressions on various measures of ex ante and realized stock market volatility.

\subsection{The ECI Index}

Figure 3 plots aggregate ECI over the sample period. There is considerable variation in the degree of concordance, with the $(\min , \max )=(0.5,0.9)$. High index values above 0.7 obtain from mid-February to mid-March, late April to early May, June, from August to September, and early December. These are periods during which the degree of bullishness or bearishness was more uniform and very high. Low ECI values, which represent conflicting expectations for returns, are found from late March to early April, late May to early June, July, October-November, and late December. Interestingly, several of the low values for aggregate ECI align with the confluence of conflicting views in response to major macro KU events.

For instance, ECI decreases from 0.8 on March 18 to .5 on March 31, which aligns perfectly with the passage of the first congressional stimulus package, the Coronavirus Aid, Relief, and Economic Security (CARES) Act, on March 26. This was also the period during which the growth rate in new COVID-19 cases was relatively high during 2020. The average daily growth rate of new cases in the US from March 18 to March 31 was 18\%. The average daily growth rate for all of 2020 was $4 \% .^{7}$ Figure 4 plots ECI against the growth rate of new COVID-19 cases

\footnotetext{
${ }^{7}$ These values are based on the daily growth rate of new cases from the 7-day moving average. Data is collected from the US Centers for Disease Control and Prevention (CDC) website.
} 
from February 4 through March 31. The two series display strong positive co-movement producing a significant correlation coefficient of $.49(\mathrm{p}$-value $=.000) .{ }^{8}$

That is, two very important events for the broad economy (and stock market) involved conflicting interpretations and produced low expectations concordance: the Congressional stimulus produced bullish views for expected returns while the high growth rate in new COVID19 cases produced bearish views. The end of December also exhibits very low values of ECI, which align with two major conflicting events: the passage of the second stimulus package, signed into law by President Trump on December 27, and the year's highest daily total of new US cases: 276,025 and 280,030 on December 30 and 31, respectively. Figure 3 plots the timing of the two stimulus packages with vertical dashed bars.

Figure 3: Aggregate KU Event ECI

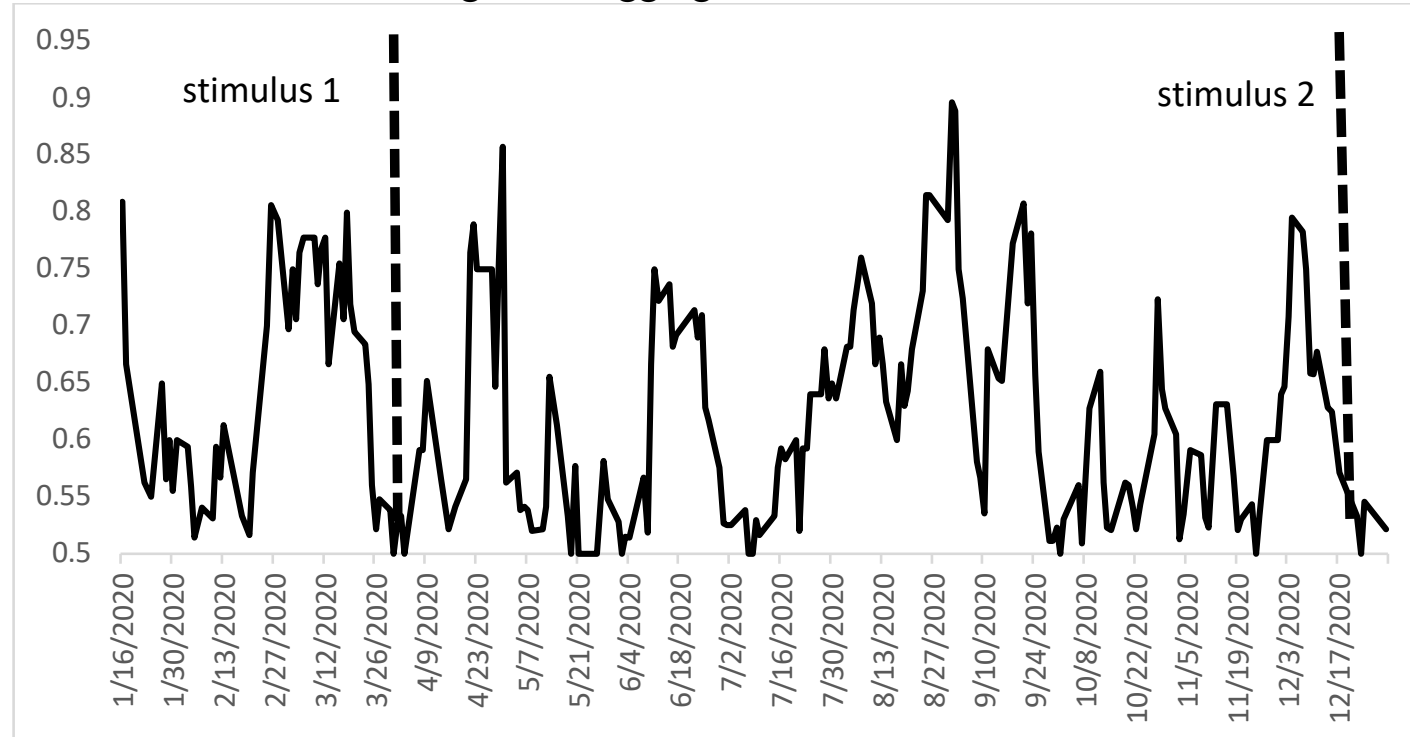

Notes: The figure plots the expectations concordance index (ECI) for an aggregate of KU events as reported in the Bloomberg News stock market wraps for 2020. The left vertical dashed line corresponds to the passage of the $\$ 2 \mathrm{~T}$ Congressional stimulus package on March 26, 2020. The right dashed line corresponds to the second stimulus package signed into law on December 27, 2020.

\footnotetext{
${ }^{8}$ To generate correlation statistics, new case data was stemmed to match the observations of ECI and stock market trading days.
} 
Figure 4: Aggregate ECI and COVID-19 Growth in New Cases

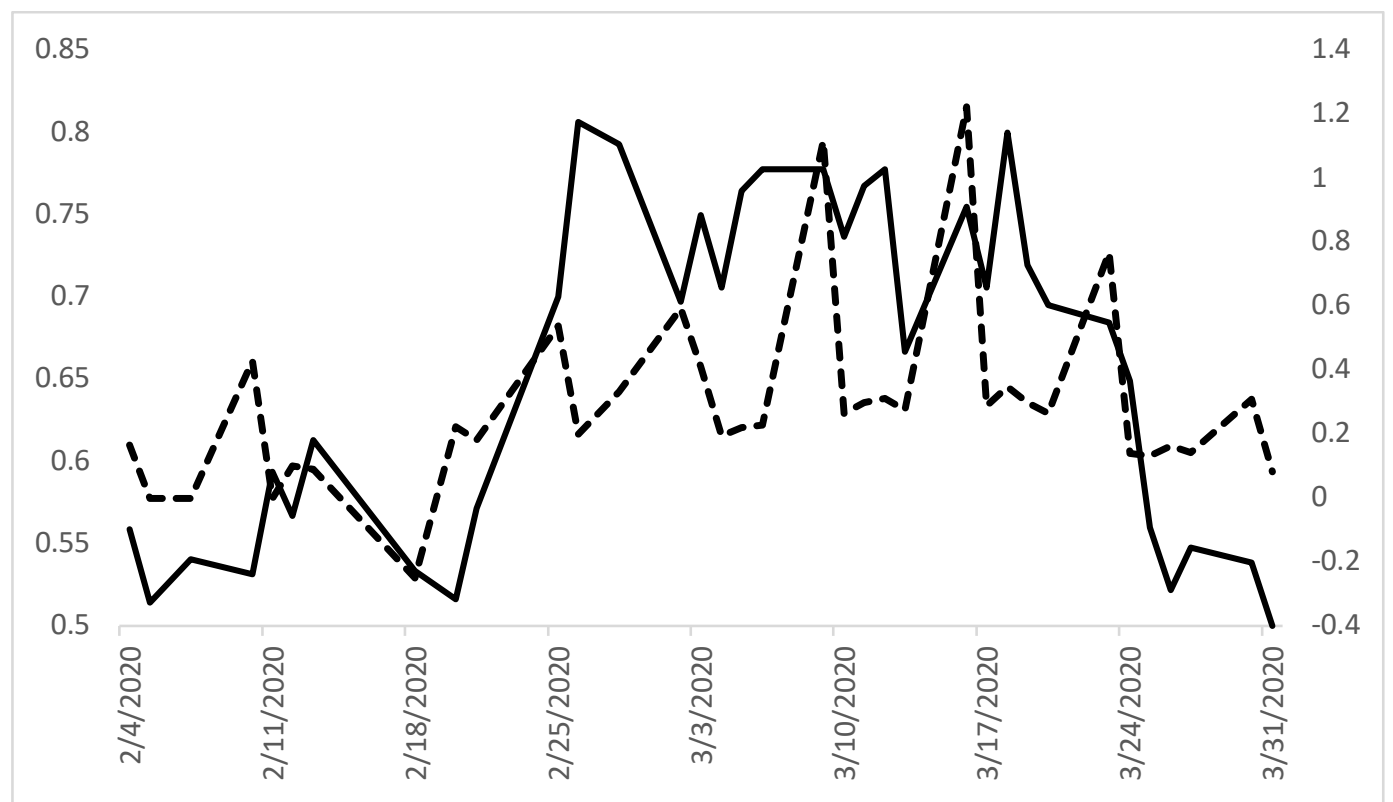

Notes: The figure plots the ECI (left axis, solid line) against the growth rate of the 7-day moving average of new COVID-19 cases (right axis, dashed line) for the period February 4, 2020, through March 31, 2020. COVID-19 case data is collected from the CDC website.

\section{Results}

The empirical analysis focuses on the explanatory power of aggregate ECI for three measures of stock market volatility. The first measure is equal to the absolute value of daily returns for the $\mathrm{S} \& \mathrm{P} 500$ Composite Index $(p)$, where $\left|R_{t-1 \mid t}\right|=\left|\left(p_{t}-p_{t-1}\right) / p_{t-1}\right|$. The second measure is the 10-day realized volatility, where $\sigma_{t-9 \mid t}^{R}=\sqrt{\sum_{i=0}^{9}\left(R_{t-i-1 \mid t-i}-\bar{R}_{t-9 \mid t}\right)^{2} /(n-1)}$. The third measure is equal to the VIX S\&P500 options-implied volatility index. ${ }^{9}$ Regression results involving OLS and GARCH estimations are reported. The standard errors for all estimates are corrected for heteroskedasticity and autocorrelation (HAC).

The first OLS regression takes the form,

$$
V_{t}=\alpha+\beta_{1} E C I_{t}+\varepsilon_{t}
$$

where $V_{t}=\left\{\left|R_{t-1 \mid t}\right|, \sigma_{t-9 \mid t}^{R}, V I X\right\}$ for each of the three volatility equations. Table 3 reports the estimation results for the full sample and for the first half of 2020. Although all coefficients on

\footnotetext{
${ }^{9}$ Data for S\&P500 daily closing prices is collected from Yahoo! Finance and is in nominal terms.
} 
ECI are positive for the full sample, only the estimation of absolute returns displays statistical significance (90\% level). However, if the regressions are run over the first half of the sample, during the period when Knightian uncertainty was widely considered to be the greatest, the coefficients on aggregate ECI all become statistically significant ( $95 \%$ for both measures of realized volatility and $90 \%$ for implied volatility) with the predicted positive sign.

Table 3: OLS Regressions of ECI on Stock Market Volatility

\begin{tabular}{|c|c|c|c|}
\hline \multicolumn{4}{|c|}{ Full Sample: January 2, 2020-December 31, 2020} \\
\hline & $\left|R_{t-1 \mid t}\right|$ & $\sigma_{t-9 \mid t}^{R}$ & VIX \\
\hline ECI & $\begin{array}{c}.043 * \\
(.024) \\
\text { adj- } R^{2}=.05\end{array}$ & $\begin{array}{c}93.713 \\
(68.457) \\
\text { adj-R }{ }^{2}=.04\end{array}$ & $\begin{array}{c}24.444 \\
(18.856) \\
\operatorname{adj}-R^{2}=.03\end{array}$ \\
\hline \multicolumn{4}{|c|}{ First Half of Sample: January 2, 2020-June 31, 2020} \\
\hline ECI & $\begin{array}{c}.080^{* *} \\
(.037) \\
\text { adj-R } \mathrm{R}^{2}=.12\end{array}$ & $\begin{array}{c}206.917 * * \\
(104.164) \\
\operatorname{adj}-R^{2}=.13 \\
\end{array}$ & $\begin{array}{c}53.244^{*} \\
(28.925) \\
\text { adj-R }{ }^{2}=.10 \\
\end{array}$ \\
\hline
\end{tabular}

Notes: Coefficients reported with HAC standard errors in parentheses. Constant included in regressions. ${ }^{*}, * *, * * *$ denote statistical significance at the $90 \%, 95 \%$, and $99 \%$ level.

The overall fit of the ECI-based volatility regressions more than doubles for absolute returns and more than triples for realized and implied volatility during the first-half of 2020 . We also find that aggregate ECI Granger causes the VIX over both the full sample ( $p$-value=.021) and the first-half of 2020 ( $p$-value=.092), but that the VIX does not Granger cause aggregate ECI across either sample period ( $\mathrm{p}$-value $=.622$ and .695 , respectively).

The second set of OLS regressions uses the ECI variable to back-out a proxy for fundamental risk and then investigate whether ECI offers explanatory power for the VIX above that of traditional risk. To isolate a fundamental risk proxy, we first regress the aggregate ECI variable on the realized 10-day volatility of S\&P500 returns $\sigma_{t-9 \mid t}^{R}$,

$$
\sigma_{t-9 \mid t}^{R}=\alpha+\beta_{1} E C I_{t}+\varepsilon_{t}^{\sigma}
$$

We then capture the residual from equation (5), which represents the explanatory power of information orthogonal to KU-based ECI on realized volatility, such that the VIX regression then takes the form,

$$
V I X_{t}=\alpha+\gamma_{1} \varepsilon_{t}^{\sigma}+\gamma_{2} E C I_{t}+\vartheta_{t}
$$


Equation (6) represents the VIX implied-volatility index as a function of both a fundamental risk component $\varepsilon_{t}^{\sigma}$ and a Knightian uncertainty component $E C I_{t}$ whose importance for explaining ex ante volatility is captured by the significance of $\gamma_{1}$ and $\gamma_{2}$, respectively. Table 4 reports results for estimating equation (6). The coefficient on fundamental risk is highly significant and positive. The coefficient on ECI is also highly significant and positive. If ECI is excluded from the VIX regression, the coefficient on fundamental risk remains positive and significant, but the adj- $\mathrm{R}^{2}$ falls from .69 to .65 . These results add to those reported in Table 3 and provide further support for the expectations concordance hypothesis in explaining return volatility under KU.

Table 4: OLS Regressions of Risk and Uncertainty on Implied Volatility

\begin{tabular}{|cc|}
\hline & VIX \\
\hline $\operatorname{RESID}\left(\gamma_{1}\right)$ & $.231 * * *$ \\
& $(.026)$ \\
$\operatorname{ECI}\left(\gamma_{2}\right)$ & $24.444 * * *$ \\
& $(8.751)$ \\
adj-R ${ }^{2}$ & .69 \\
\hline
\end{tabular}

Notes: RESID is the residual from the regression of aggregate ECI on the 10-day realized standard deviation of returns $\sigma_{t-9 \mid t}^{R}$. Coefficients are reported with HAC standard errors in parentheses. *, **, *** denote statistical significance at the $90 \%, 95 \%$, and $99 \%$ level.

The third set of regressions are based on GARCH-X specifications which include an exogenous regressor in the conditional variance equation - in this case, the aggregate ECI variable.

ARCH/GARCH models focus on the variance of the dependent variable as a function of past values of the dependent variable and independent, or exogenous, variables if included. ${ }^{10}$ The mean equation takes the form,

$$
R_{t-1 \mid t}^{S P 500}=c+\epsilon_{t}
$$

where $c$ is a constant and $\epsilon_{t}$ is a Gaussian IID mean-zero error term with constant variance. The conditional variance for a $\operatorname{GARCH}(q, p)-X$ model of realized volatility can then be expressed as,

$$
\sigma_{t-9 \mid t}^{2}=\omega+\sum_{i=1}^{q} \beta_{i} \sigma_{t-i}^{2}+\sum_{j=1}^{p} \alpha_{j} \epsilon_{t-j}^{2}+\rho Z_{t}+\vartheta_{t}
$$

where $q$ denotes the number of first-order autoregressive forecast variance terms, $p$ denotes the order of the moving average ARCH terms, $\mathrm{Z}$ denotes aggregate ECI, and $\vartheta_{t}$ is the assumed Gaussian IID error term. Given our hypothesis that greater expectations concordance drives

${ }^{10}$ For GARCH (Generalized ARCH) models, see Bollerslev (1986) and Taylor (1986). 
greater market volatility, we would expect $\rho>0$ and statistically significant in explaining the conditional volatility of realized S\&P500 returns. We focus on the variance equation and find that a GARCH(1,1)-X model generates the following coefficients (with p-values in parentheses): $\omega=-.000(.000), \alpha=.341(.014), \beta=.538(.000)$, and $\rho=.0004(.000)$. The results suggest that last period's forecast variance of returns is positive and significant, news about last period's volatility is positive and significant, and the impact from ECI is positive and significant. ${ }^{11}$

Residual diagnostics from the $\mathrm{GARCH}(1,1)-\mathrm{X}$ model for conditional variance of returns also shed light on the improvements in model fit from including ECI in the specification for market volatility. First, because stock return volatility is persistent, we can look at the sum of $\alpha$ and $\beta$ coefficients; if $\alpha+\beta \approx 1$, then conditional variance is very persistent. From the $\operatorname{GARCH}(1,1)$ ECI model estimates, we see that $\alpha+\beta=.88$, compared to the higher values of $\alpha+\beta=.95$ for the baseline GARCH $(1,1)$ model without ECI in the variance equation. This suggests that including ECI in the return variance specification reduces the degree of persistence documented throughout the volatility literature. Second, it is also a stylized fact that stock return volatility has fat-tail distributions with high levels of kurtosis. ${ }^{12}$ The GARCH(1,1)-ECI model generates a Jarque-Bera test statistic of 42.26 for normality of residuals, which, although it rejects normality with a $p$-value $=.000$, is much lower than the JB test statistic of 215.78 for the baseline model excluding ECI.

\section{Conclusion}

Non-repetitive events such as Congressional stimulus negotiations or a pandemic cause unforeseeable change, and thus Knightian uncertainty, in the process driving stock market prices. Consequently, market expectations of returns in response to such events cannot be assessed with stochastic, or probabilistic, rules based on past data. Rather, market participants will interpret such events as being either more bullish or bearish for expected returns. The degree of similarity or conflict in views will, therefore, have differential impacts on return volatility: greater expectations concordance is hypothesized to produce reinforcing effects and greater return volatility.

We identify historical events reported as driving daily returns from Bloomberg News stock market wrap reports to assess the market's qualitative (bullish or bearish) interpretations for expected returns over the year 2020. By quantifying the views with +1 s and -1 s we are able to develop a novel Expectations Concordance Index, which we relate to both ex ante and realized measures of stock market volatility. ECI is low when major events like the passage of

\footnotetext{
${ }^{11}$ The results are similar for GARCH models of implied volatility and for including ECI in the mean equation.

${ }^{12}$ For an extensive discussion see Campbell et al. (1997) and references therein.
} 
Congressional stimulus packages and concurrent increases in COVID-19 cases produce conflicting views.

The main empirical finding of this study is that greater ECI across an aggregate of all interpretations of KU events leads to greater stock market volatility. That is, when market expectations are reinforcing, whether bullish or bearish on the whole, the volatility of stock returns is greater. By contrast, lower aggregate ECI leads to lower return volatility as conflicting expectations somewhat offset producing a stabilizing effect. The empirical findings are robust to OLS and GARCH-X estimates and to realized and implied volatility (VIX) measures. As a whole, this study speaks to the benefit of narrative analytics for understanding the importance of Knightian uncertainty in driving financial market outcomes. 


\section{References}

Alexopoulos, M. and J. Cohen (2015), “The Power of Print: Uncertainty Shocks, Markets, and the Economy," International Review of Economics and Finance, 40, 8-28.

Baker, S.R., Bloom, N. and S.J. Davis (2016), "Measuring Economic Policy Uncertainty," Quarterly Journal of Economics, 131(4), 1593-1636.

Baker, S.R., Bloom, N., Davis, S.J., and M. Sammon (2019), "What Triggers Stock Market Jumps?" Working Paper.

Baker, S.R., Bloom, N., Davis, S.J., Kost, K., Sammon, M. and T. Viratyosin. (2020a), “The Unprecedented Stock Market Reaction to COVID-19," Review of Asset Pricing Studies, 10(4), $742-758$.

Baker, S.R., Bloom, N., Davis, S., and K. Kost (2020b), "Policy News and Stock Market Volatility," Working Paper.

Barinov, A. (2013), “Analyst Disagreement and Aggregate Volatility Risk," Journal of Financial and Quantitative Analysis, 48(6),1877-1900.

Bekiros, S., Gupta, R. and C. Kyei (2016), “On Economic Uncertainty, Stock Market Predictability and Nonlinear Spillover Effects," North American Journal of Economics and Finance, 36, 184-191.

Bollerslev, T. (1986), “Generalized Autoregressive Conditional Heteroskedasticity,” Journal of Econometrics, 31, 307-327.

Branger, N., Schlag, C. and L. Wu (2015), "Nobody is Perfect: Asset Pricing and Long-Run Survival when Heterogeneous Investors Exhibit Different Kinds of Filtering Errors," Journal of Economic Dynamics and Control, 61, 303-333.

Campbell, J.Y., Giglio, S., Polk, C., and R. Turley (2018), “An Intertemporal CAPM with Stochastic Volatility,” Journal of Financial Economics, 128(2), 207-233.

Campbell, J.Y., Lo, A.W., and A.C. MacKinlay (1997), The Econometrics of Financial Markets, Princeton University Press.

Cochrane, J. (2005), Asset Pricing, Princeton University Press. 
Dzielinski, M., and H. Hasselhoft (2017), "News Tone Dispersion and Investor Disagreement." Working paper, Stockholm Business School, 2017.

Engle, R. (1982), “Autoregressive Conditional Heteroskedasticity with Estimates of Variance of UK Inflation,” Econometrica, 50(4), 987-1008.

Friberg, R. and T. Seiler (2017), "Risk and Ambiguity in 10Ks: An Examination of Cash Holding and Derivatives Use," Journal of Corporate Finance, 45, 608-631.

Frydman, R., Goldberg, M.D. and N. Mangee (2015), "Knightian Uncertainty and Stock- Price Movements: Why the REH Present-Value Model Failed Empirically," Economics: The OpenAccess, Open-Assessment E-Journal, 9, 1-50.

hull

Hansen, S. (2015), "Cross-Sectional Asset Pricing with Heterogeneous Preferences and Beliefs," Journal of Economic Dynamics and Control, 58, 125-151.

Hendry, D.F. (2018), “Deciding Between Alternative Approaches in Macroeconomics,” International Journal of Forecasting, 34(1), 119-135.

Hendry, D.F. and J.A. Doornik (2014), Empirical Model Discovery and Theory Evaluation: Automatic Selection Methods in Econometrics, MIT Press.

Hong, H., and J.C. Stein (2007), "Disagreement and the Stock Market," Journal of Economic Perspectives, 21(2): 109-128.

Hull, J. and A. White (1987), "The Pricing of Options on Assets with Stochastic Volatilities," Journal of Finance, 42(2), 281-300.

Knight, F. (1921). Risk, Uncertainty, and Profit, Houghton Mifflin.

Liu, L. and T. Zhang (2015), "Economic Policy Uncertainty and Stock Market Volatility," Finance Research Letters, 15(C), 99-105.

Loughran, T. and B. McDonald (2011), "When is a Liability Not a Liability? Textual Analysis, Dictionaries, and 10-Ks," Journal of Finance, 66, 35-65.

Manela, A. and A. Moreira (2017), "News Implied Volatility and Disaster Concerns," Journal of Financial Economics, 123(1), 137-162. 
Mangee, N. (2021a), “A New Explanation for Samuelson's Dictum and the Stock Market: Novel Events and Knightian Uncertainty,” SURE Journal, 21/03, http://dx.doi.org/10.26021/10831.

Mangee, N. (2021b), How Novelty and Narratives Drive the Stock Market: Black Swans, Animal Spirits, and Scapegoats, Cambridge University Press, forthcoming.

Mangee, N. and M.D. Goldberg (2020), “A Cointegrated VAR Analysis of Stock Price Models: Fundamentals, Psychology and Structural Change," Journal of Behavioral Finance, 21(4), 352368.

Taylor, S. (1986), Modeling Financial Time Series, John Wiley and Sons.

Wiggins, J. (1987), “Option Values under Stochastic Volatility: Theory and Empirical Estimates, Journal of Financial Economics, 19(2), 351-372. 